\title{
A Spatial Model of Qualitative Exposure, Province of Neuquén, Argentina
}

\author{
Diana Elba, de Pietri ${ }^{1,2 *}$, Dietrich, Patricia ${ }^{2}$, Carcagno, Alejandro², de Titto, Ernesto ${ }^{1}$
}

${ }^{1}$ National Direction of Determinants of Health and Research, Ministry of Health of the Nation, Argentina

${ }^{2}$ Metropolitan Center Information, Faculty of Architecture, Design and Urbanism, UBA, Argentina

*Corresponding author: Dr. Diana Elba De Pietri, National Direction of Determinants of Health and Research, Ministry of Health of the Nation, $12^{\text {th }}$ floor, C1073ABA; Metropolitan Center Information, Faculty of Architecture, Design and Urbanism, UBA, University town, C1428BFA, Argentina.E-mail: depietrid@hotmail.com; pdietr@fadu.uba.ar

\begin{abstract}
Increased demand for natural resources by society generates impact that threatens its sustainability. For this reason, it is important to have an appropriate instrument to obtain appropriate capacity for environmental and land management.

In this work the reference area does not correspond to a political-administrative unit but summarizes an environmental condition. Thus inferences obtained from analysis of mortality, may indicate a differential behaviour about variations in environmental conditions.

The objective was to validate environmental exposure defined by a spatial model of the territory of Neuquén, Argentina, through the analysis of mortality in the period 2000-2012.

The methodology used was the multicriteria evaluation with GIS. The different productive activities in the study area are selected and transformed into a single measure to compare different sites together. A gradient of sites are defined according to the adverse ambient conditions. To validate these sites, they are confronted with the deaths during the period 2000-2012. The spatial model was developed in order to stratify the territory to maximize exposure contrast.

The accumulated number of total deaths in relation to the reference population average unchanged in time. Neither the dominant cause of death varied with time. However, variability in mortality rates is found by incorporating the spatial dimension. More deaths were observed in the exposure zones compared to non-exposure. In the area categorized by the spatial model as degraded area increased mortality of neoplasms, diseases of the circulatory system, endocrine, nutritional and metabolic diseases was observed; infectious or parasitic diseases and diseases of the musculoskeletal system and connective tissue.
\end{abstract}

Received date: November 22, 2015

Accepted date: November 28, 2015 Published date: December 05, 2015

Citation: De Pietri, D., et al. A Spatial Model of Qualitative Exposure, Province of Neuquén, Argentina. (2015) J Environ Health Sci 1(4): 1-9.

DOI: $10.15436 / 2378-6841.15 .025$

\section{Introduction}

The combination of population growth and increasing per capita demand for energy, water and all kinds of resources on the biophysical system generated unprecedented levels of pressure and impact that threaten their sustainability. For this reason, it is a great challenge to achieve adequate capacity for environmental and land management to contribute to the harmonious and integrated development of resource availability, economic activity and urban sprawl. However, the aforementioned aspects conflict with a number of issues of environmental origin.

There are various impacts depending on the type of productive activity and its dynamics. For instance among the most obvious and significant environmental impacts the diverse and multiple forms of pollution are described, with particular reference to the extractive industries (oil, mining, etc.); habitat destruction and biodiversity, involving damage to fauna and flora of a site can also cause flooding of land by deforestation; displacement of the population, the breakdown or deterioration of the social fabric and fam- 
ily bonding (Petras and Veltmeyer, 2007). Other important impacts are related to indigenous peoples -for the effects generated both owned as to resources that disponen-, their cultural identity and their modes of political organization; and with the ownership model of strategic resources and utilities (oil, gas, minerals, electricity, water, telecommunications) (Uharte, 2005).

Impacts such as those mentioned may be the main environmental determinants of population health. Several efforts have been made to understand the effects of environmental changes and understand the disease processes that may be associated (Corvalan, 1999). Üstün \& Corvalan, 2006 detailed the impact of environmental health risks, with reference to more than 80 diseases and injuries. Knowledge in the field of these interactions can serve as a basis for designing preventive strategies and more effective public health.

The spatial epidemiology and geographic information systems (GIS) have proven to be a key to study patterns and spatial variations of disease tool. In these analyzes of spatial aspects of environmental problems converge concepts of epidemiology, statistics and computer tools. Usually, rates of disease or mortality for the study areas are obtained by aggregating cases. Codes are employees of the municipality or province (traditional method of geo-coding). In this work the reference area corresponds with environmental units and not for a political-administrative unit (province, departments). Thus the inferences resulting from the analysis of mortality, may indicate a differential behavior variations in environmental conditions.

The objective was to validate environmental exposure defined by a spatial model of the territory of Neuquén through the analysis of mortality in the period 2000-2012.

\section{Materials and Methods}

This paper focuses on the approach of a parameterizable method to estimate the risk exposure of the population. Productive activities that generate adverse environments can be determinants of health damage.

The spatial model was based on land use. At the same time, land uses were characterized with an ecological perspective (ecosystem integrity). It is to measure the capacity of the territory in terms of the conditions of sustainability.

The ecosystem integrity of a site is defined as the ability of the ecosystem to support and maintain a community of organisms, whose species composition, diversity and functional organization comparable to natural habitats within a particular region. In this context, a system has ecological integrity if it is able to maintain its structure and functioning despite changing environmental conditions by natural or human reasons (Junta de Andalusia 2015).

For land use it is understood as actions, activities and interventions that people do on a particular type of surface to produce or maintain it. But some activities are the main cause of environmental degradation. A non-degraded ecosystem is a source of wealth for society. Degradation due to overexploitation of resources, may serve an economic purpose of short term, medium and long term has a direct and negative impact on social welfare (Velez Restrepo \& A. Gómez Sal, 2008).

The methodology used to measure the degree of ecosystem integrity of the different land uses will be the multi-criteria evaluation with GIS (Eastman 1993, Barredo 1996, Santos

\section{Preciado 1997, Florent 2001, De Pietri 2011).}

The degree of ecosystem integrity of a site will be analyzed for example by high consumption of energy and/or water; increases residues; population growth, loss of natural resources, etc. The analysis process is to define credibility (probability) that an adverse effect on the site as a result of the production activity occurs. Environmental adversity is an impact on the health of the population. It is defined as population exposed to adverse environments that people who lived in degraded by human activities assuming the contact person with the pollutant.

\section{Construction of the spatial model}

It was taken as a case study to the Neuquén province given free access to spatial information across the provincial IDE (COPADE, 2014) (figure 1). The land cover /land use maps were extracted. This information was grouped following a criterion of threat or danger. The different risk levels were characterized by the following sequence:
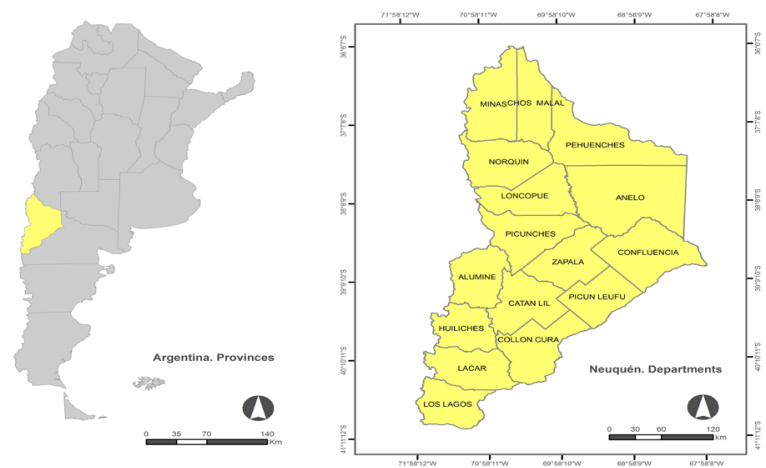

Figure 1: Location of the province of Neuquén in Argentina, and geographical location of the different departments (administrative units) in the province of Neuquén.

A. Land use with maximum transformation of the natural ecosystem. Lost its resilience. Restricts the land for other land uses because of its environmental impact over long periods (over the span of a generation). Different levels of pollution of natural resources and its consequences on the health of the population are described. Example: Mining extraction wells subsurface oil and gas by hydraulic fracturing and conventionally, quarries, mines. Power generation: central/ hydroelectric plants.

B. Land use that may eventually lead to situations of risk to people living in the neighborhood. Risks of accidents with possible loss of hazardous substances and generation of fatal traffic events (shocks, spills): pipelines, land transport. Risks handling of hazardous substances and waste generation. Inappropriate use of fuels and other hazardous substances: industries, sawmills, service stations, fuel tanks, treatment plants, pumping plant.

C. Those land uses that are compatible with residential use. Eventually they may present a risk to health and the environment due to misuse and / or overuse of any component at any stage of the production cycle. The environmental impacts generated impact on health in later stages of construction or due to improper maintenance. Examples: transmission of waterborne diseases. decreased water quality; water supply (aqueducts), storage tanks, industries that process natural products (agro-industry and primary production) 
D. Land use without apparent ill effect. Ecosystem conservation areas and / or protection of green spaces: areas of native forests, national parks and provincial.

Simultaneously the degree of spatial extent of each production activity was analyzed by fuzzy membership functions. Diffuse functions facilitated the definition of a gradient of environmental affectation.

For the construction of these functions was required to define two measures represent the distances on the ground (independent variable). The first measure distance indicates the distance with full involvement of the territory by the activity (maximum environmental impact -max ei-), the second is the distance at which no environmental impact (minimal environmental impact -min ei-). There is a linear variation between the two measures (Figure 2). These distances are converted to values of ecosystem integrity in a range of values ranging from " 0 " representing harsh environments to " 1 " indicating conditions without negative impacts on the environment.

\section{FUZZY MEMBERSHIP FUNCTIONS. CRITERIA FOR CONSTRUCTION.}

A1 EXTRACTION OF GAS AND OIL FROM THE GROUND. CONVENTIONAL WELLS The affected area is composed of drilling rigs, parking and maneuvering areas for trucks, equipment, processing facilities, treatment facilities and / or transportation. The greatest danger is given leakage well casings, pipes and storage tanks.

A2 EXTRACTION OF GAS AND OIL FROM THE GROUND BY HYDRAULIC FRACTURING Besides mentioned in the previous item, underground streams laterals with potential returns are added. Among the dangers changes hydrological cycles in both quantity and quality, given the volume of water and sand needed for the production process are cited.

A

A3 MINERAL EXTRACTION. MINING AND QUARRYING

Activities with high occupation and land transformation. Both surface and underground mining include production area, unloading, storage and removal of large volumes of material and waste. Possible dangers for heap leaching, modification of drainage by digging and blasting explosions.

A4 HYDROELECTRIC POWER

They occupy large areas. Includes permanent landscape modifications, alterations flow basins. It can involve population displacement and resettlement. He joined structures such as concrete. Includes connection to transformer substations. There is a risk for dam failure for urban and rural settlements.

B1 ROAD NETWORK

The use of machinery leads to increased traffic. Exposure can occur by emissions of gases and dust in the air. It can also be unsafe for increased likelihood of accidents .

B2 PIPELINES / GAS PIPELINES

Among the elements are access roads or maintenance roads; receiving stations, dispatch and control, and pumping or compressor stations. Pipelines breaking can cause significant environmental damage. Leaks or ruptures of the pipelines can cause explosions and fires.

B3 STATIONS SELLING FUEL / FUEL PLANTS

Health risk for fire or explosion, and environmental contamination from spills of hazardous substances and exposure to

B gasoline vapors

B4 INDUSTRY / SAWMILL

Industrial parks, isolated industries. Danger of environmental contamination and exposure to hazardous substances

B5 TREATMENT PLANTS / PUMPING

There may be danger of breakage, spills and / or leaks from storage areas or areas of chemical sludge deposit. Waste generated in the pumping stations and transfer, can cause potentially contaminating soil, surface water and groundwater.

B6 GEOTHERMAL STATIONS

They can emit pollutants transported by geothermal power. The area affected by the project construction area covers civil works, temporary facilities, platforms, access, lines of geothermal fluids (ponds, pipelines, steam pipelines and separator stations), roads, powerhouse, substation.

C1 AQUEDUCT

The danger is associated with microbiological quality of water, hygiene and sanitation.

C2 AGROINDUSTRY

C Productive zones of smoky, beer, chocolate, pinion derivatives, honey, cheese, wine, sweets and liqueurs, olive. Presence of chemical, physical or biological in the water. Industrial discharge; Spill. leaching

\section{C3 PRIMARY PRODUCTION}

Producing areas of beef, pigs, goats, rabbits, fine fruit, vegetables, nuts, turkey, trout, other. Presence of chemical, physical or biological in the water. Drain untreated

D1 FOREST AREAS, PLANTATIONS, BUSHES AND MALLINS

Provide critical ecosystem services, involved in the climate and water regulation. Positive environmental impact

D D2 2 PROTECTED AREAS

Natural parks. National and provincial parks. Provide critical ecosystem services, involved in the climate and water regulation. Positive environmental impact

\begin{tabular}{|c|c|}
\hline $\begin{array}{l}\text { Max.env } \\
\text { i mpact } \\
\text { meters }\end{array}$ & $\begin{array}{l}\text { Min. env. } \\
\text { I m p a c t } \\
\text { meters }\end{array}$ \\
\hline 200 & 1000 \\
\hline 200 & 4000 \\
\hline 500 & 2000 \\
\hline 500 & 4000 \\
\hline 50 & 100 \\
\hline 100 & 200 \\
\hline 300 & 500 \\
\hline 500 & 1000 \\
\hline 100 & 200 \\
\hline 500 & 1500 \\
\hline 100 & 200 \\
\hline 100 & 300 \\
\hline 100 & 200 \\
\hline 500 & 0 \\
\hline 1000 & 0 \\
\hline
\end{tabular}




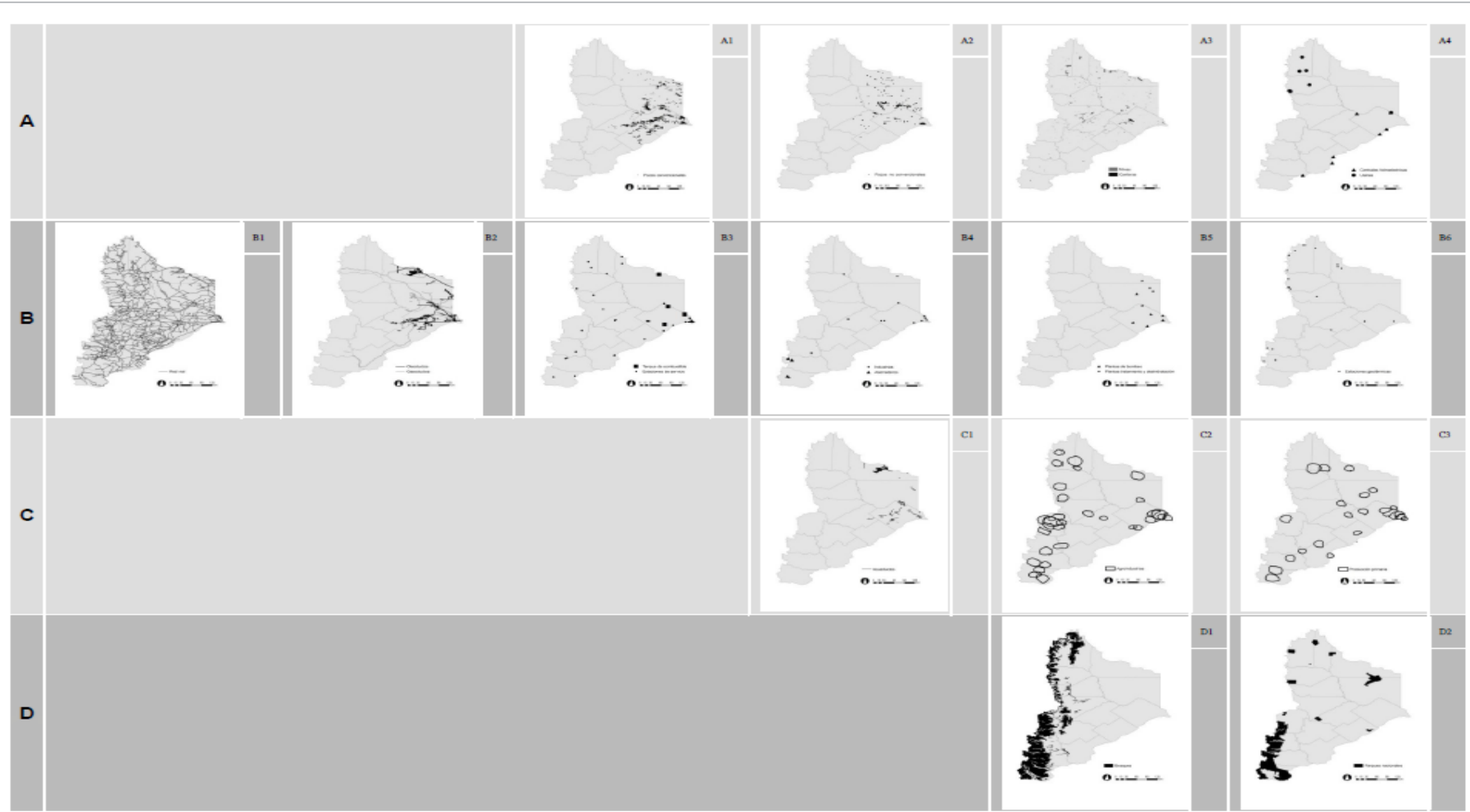

Figure 2: Description of geographic and non-geographic data of the study area, and criteria for the development of fuzzy membership functions of each land use.

A multivariate index is constructed from these variables (geo-referenced weighted transformed, and standardized) by a weighted linear sum. The resulting map is generated by the integrated land use information, that influence differentially according to their weight. For example, sites with one or more activities at risk of contamination are to discriminate low values. The values (ri) higher sites represent the largest ecosystem integrity as opposed to the lowest values which indicate a degraded site. This procedure was performed using the multi-tool Idrisi [Clark Labs, USA] from which a map was obtained.

\section{Geo-death and allocation of reference population}

The total annual deaths in the province of Neuquén were geo-referenced in the greater spatial detail referenced in the database. Death at the village, commune, neighborhood and/or site level was located. The database used is for the period 2000-2012, but given the low values of accumulated mortality death in two periods: A: 2000-2006 (data do not include data obtained in 2003) and B: 2007-2012.

Death data was provided by Ministry of Health of the Nation. Demographic data were provided by National Institute of Statistics and Censuses. The spatial unit was the census radius. The population census for the 2001 and 2010 (INDEC 2001, 2010).

Spatial analysis unit was delimited for the allocation of the number of deaths and the total reference population. The guidance set forth in (United Nations, 2000) was followed. Population density at a disaggregated territorial level was calculated (CEPAL 2012, Candia, 2011).

Sites differ according to the population density of census radios. This procedure was performed for the national census of 2001 and 2010. Census radios that had 10 or more inhabitants per $\mathrm{km} 2$ urban area formed differing from those with lower population density (rural). In these urban areas, sub-areas were defined as census radios with 10 or more inhabitants / km2 were contiguous, obtaining a single value of total population.

\section{Measurement of relative risk}

Sectors with different degrees of ecosystem integrity were defined. They use the method of "mean and standard deviation" provided in the Arcgis10.2 [ESRI, USA program (21). 5 zones were generated. The degraded area was delimited by the first two zones (representing the model lower values); the area with ecosystem integrity was defined by the last two areas (representing the highest values of the model) and the remaining area is the intermediate values of the model. It was not included in the analysis.

Overall mortality is the number of deaths from all causes of disease in all age groups and for both sexes. Mortality expresses the dynamics of the deaths occurred in populations over time and space, and level comparisons only major causes of death will be made. The classification of causes of death was performed according to the International Statistical Classification of Diseases and Related Health Problems - (CIE-10, 1992).

The mortality rate was calculated from the number of geo-deaths and the total population. The cumulative rates (6 years) were expressed per 1,000 population at risk and specific rates (by cause of death) per 10,000 inhabitants at risk. It is assumed that in the period of time the rate has remained constant. 
The relative risk of living in degraded areas (population at risk) regarding areas with ecosystem integrity (unexposed population) will be measured by contingency table "exposure / disease." Spatial stratification model will be validated by the number of deaths. Statistical analysis was carried out with a significance level of $\alpha=0.05$; (42), the EPIDAT 3.0 [OPS, USA Xunta de Galicia] program was used.

\section{Results}

The spatial model was built based on information from productive activities in the territory of Neuquén. This model represents degradation of the ecological system and therefore the probability of exposure of the population to an adverse environment (Figure 3).

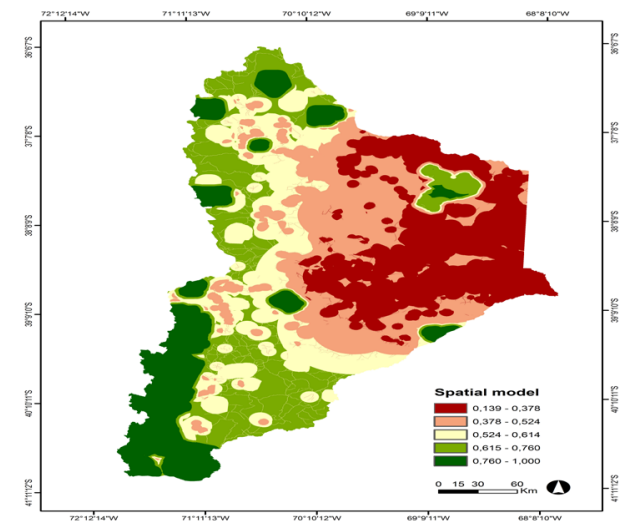

Figure 3: Spatial model generated from a multi-criteria evaluation. Explanation in the text

Consistent methods were used to establish a single value that summarizes environmental conditions of ecosystem integrity. The area with the greatest environmental impact is represented by red / pink tones. It covers a large territory (46\%) distributed between the center and east of the region. The area with less adversity is represented by green shades, covers $34 \%$ of the province and mainly distributed west of the study area. The remaining area $(20 \%)$ represents gradient conditions between the two ends for the purpose of manuscript were not considered. The dichotomous classification of territory "ecosystem integrity / degraded ecosystems", defined a threshold. This is easy to establish a criterion to define the population as "exposed / unexposed". The value of ecosystem integrity of the territory is a measure of exposure.

$10 \%$ of all deaths were not geo-referenced locality level because the person did not reside in the province, or because they consigned the data. In addition, $5 \%$ of the deaths occurred in the area of the intermediate gradient.

The geo-deaths are distributed in 199 and 188 sites (during 2000-2006 or 2007-2012). The cumulative total number of deaths in relation to the average reference population does not vary between the periods analyzed. The cumulative mortality rate for 2000-2006 and 2007-2012 was 23,978 and 24,901. That is, in the province of Neuquén, every 6 years died between 23 and 24 people per 1000 inhabitants.

However, the cumulative total number of deaths in relation to the reference population was higher in exposure area in the area of non-exposure (OR: 1.25 IC (95\%) 1.174- 1.338) for the second 2007-2012. The first period showed no statistically significant association (OR: 1.06 IC (95\%) 0.996-1.149).

Analyzing the variation of deaths between periods (2000-2006 and 2007-2012) in each of the areas showed very light to no change. In exposed area it was OR: 1.06 IC (95\%) 1.033-1.092. In unexposed area it was OR: 0.90 IC (95\%) 0.8260.994 .

That is, mortality in the exposure area turned out to be higher than in the unexposed area in the second period. In addition, it was observed that in general (in the study area) and in particular (in the zones) no variation in mortality over time. Ergo, mortality in the first period must be greater in the exposure area in relation to the area of non-exposure. Therefore the incorporation of the spatial dimension to the analysis of the data reveals variability in mortality rates in the study area.

The disaggregation of values by major cause of mortality shown (figure 4). The dominant causes correspond with tumors; diseases of the circulatory system; respiratory; and external causes.

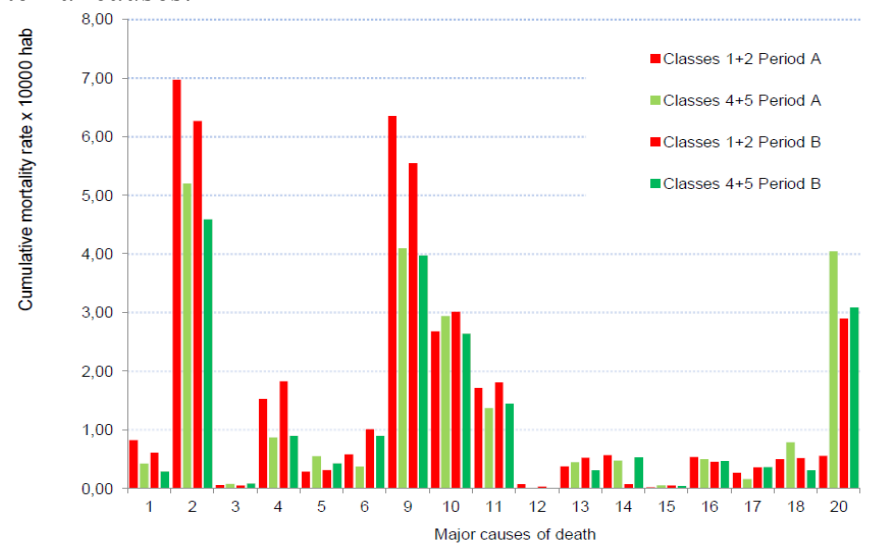

Figure 4: Bar chart. Specific cumulative mortality rates. Major causes of death:

1. Chapter I Certain infectious and parasitic diseases;

2. Chapter II Neoplasms;

3. Chapter III Diseases of the blood and blood-forming organs and other disorders involving the immune mechanism;

4. Chapter IV Endocrine, nutritional and metabolic diseases;

5. Chapter V Mental and behavioral disorders;

6. Chapter VI Diseases of the nervous system;

9. Chapter IX Diseases of the circulatory system;

10. Chapter X Diseases of the respiratory system;

11. Chapter XI Diseases of the digestive system;

12. Chapter XII Diseases of the skin and subcutaneous tissue;

13. Chapter XIII Diseases of the musculoskeletal system and connective tissue;

14. Chapter XIV Diseases of the genitourinary system;

15. Chapter XV Pregnancy, childbirth and postpartum;

16. Chapter XVI Certain conditions originating in the perinatal period; 17. Chapter XVII Congenital malformations, deformations and chromosomal abnormalities;

18. Chapter XVIII Symptoms, signs and abnormal clinical and laboratory findings, not elsewhere classified;

20. Chapter XX External causes.

The number of sites where at least one death occurs is associated with the number of deaths by cause. There is a positive relationship. That is, by increasing the number of dead sites, also increases the total number of specific deaths. The trend is similar for both periods (Figure 5). Tags only in period B (20072012). Those points are above the estimated line (exponential 
function) values indicate higher than expected mortality for this cause and vice versa. For example, a sequence of maps presented to show the change of the spatial arrangement of the different causes of death according to density. The tool used was ArcGis kernel density.

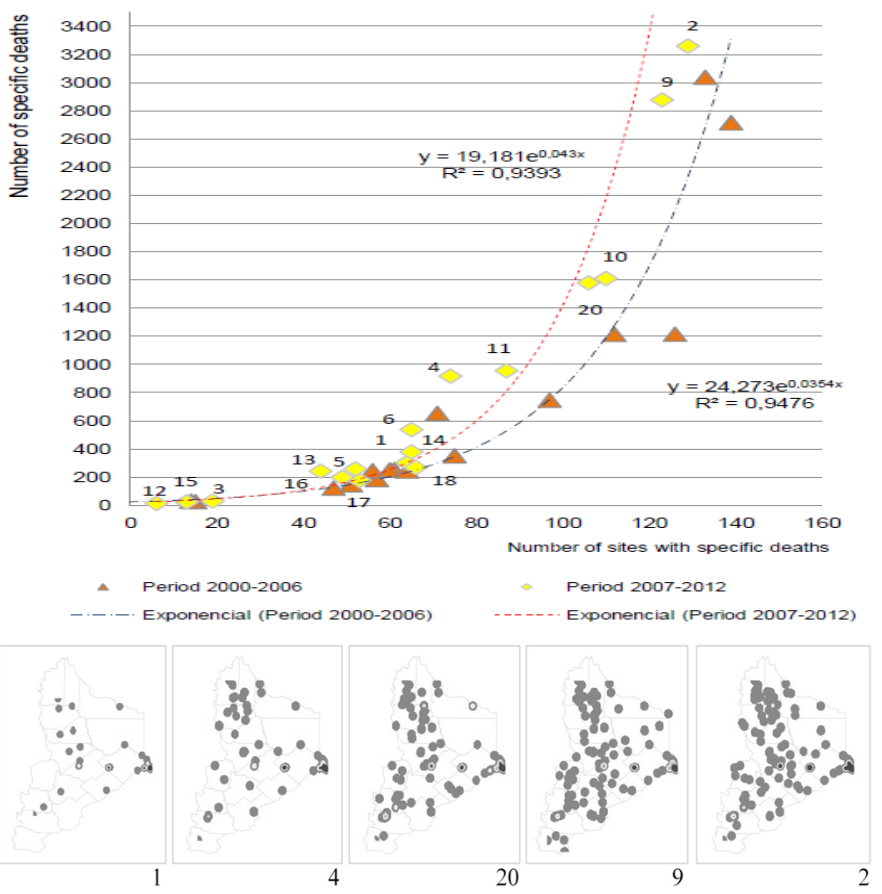

Figure 5: Site-specific deaths. Chart shows the relationship between the abundance of specific functions and the number of sites with at least one death. The sequence of maps showing the distribution of the sites according to number and cause of death

Following the evaluation of the association between cause of death and the area where the event occurs is described. Also significant variations between periods indicated:

1. Chapter I Certain infectious and parasitic diseases. An average of 4 to 5 deaths expected by 10,000 people per site every six years. Increases cause of death in exposed sites in relation to the non-exposed sites in the period 2000-2006 (OR: 1.96 IC (95\%) 1.184-3.233) and 2007-2012 (OR: 2.13 IC (95\%) 1.243-3.639). That is, there is a $66.2 \%$ and $68.1 \%$ probability that death from this cause is associated with the degraded area. This area constitutes a risk factor. However mortality in degraded sites in the area was lower in the period 2007-2012 compared to 2000-2006 (OR: 0.73 IC (95\%) 0.625-0.854).

2. Chapter II Neoplasias. Every six years an average of 25 or 36 expected deaths per 10,000 people per site. Increases in deaths from this cause in the area degraded in relation to the area with ecosystem integrity in the period 2000-2006 (OR: 1.34 IC (95\%) 1.162 -1.552) and 2007-2012 (OR: 1.37 IC (95\%) 1.195 $-1.568)$. That is, there is a $57.3 \%$ and $57.8 \%$ probability that death from this cause is associated with the degraded area. This area constitutes a risk factor. However although the association is positive and precise, this case could provide more information to be analyzed in greater disaggregation.

3. Chapter III Diseases of the blood and blood-forming organs and other disorders involving the immune mechanism. Every six years an average of 1 or 2 deaths per 10,000 population expected by site. Mortality rates from this cause are low and its variations are not significant.
4. Chapter IV Endocrine, nutritional and metabolic diseases. Every six years an average of 12 or 13 expected deaths per 10,000 people per site. There are increases in deaths from this cause in the area degraded in relation to the area with ecosystem integrity in the period 2000-2006 (OR: 1.76 IC (95\%) $1.240-1.250)$ and 2007-2012 (OR: 2.05 IC (95\%) 1.511- 2.771). That is, there is $63.8 \%$ and $67.28 \%$ probability that death from this cause is associated with the degraded area. This area constitutes a risk factor. Also mortality in degraded sites in the area increased in the period 2007-2012 compared to 2000-2006 (OR: 1.20 IC (95\%) 1.076-1.330)

5. Chapter V Mental and behavioral disorders. Every six years an average of 3 or 4 is expected deaths per 10,000 people per site. This cause mortality was lower in the degraded area in relation to the area with ecosystem integrity in the period 2000-2006 (OR: 0.52 IC (95\%) 0.329-0.837). Therefore, 34.2\% probability that death from this cause is associated with degraded area.

6. Chapter VI Diseases of the nervous system. Every six years an average of 8-9 deaths per 10,000 inhabitants is expected by site. No significant differences between areas for the same period were observed. However, mortality from this cause increased in the period 2007-2012 compared to 2000-2006 in the degraded area (OR: 1.74 IC (95\%), 1.483-2.041) and the area ecosystem integrity (OR: 2.43 IC (95\%) 1.331-4.433).

9. Chapter IX Diseases of the circulatory system. Every 6 years on average expected 23 to 24 deaths per 10,000 people per site. Increase deaths in the area degraded in relation to the area with ecosystem integrity in the period 2000-2006 (OR: 1.55 IC (95\%) 1.321-1.827) and 2007-2012 (OR: 1.40 IC (95\%) 1.208-1.617). That is, there is a $60.8 \%$ and $58.3 \%$ probability that death from this cause is associated with the degraded area. This area constitutes a risk factor.

10. Chapter X Diseases of the respiratory system. Every 6 years on average expected 14 to 15 deaths per 10,000 people per site. Mortality rates from this cause are intermediate although variations between zones and / or periods are not significant.

11. Chapter XI Diseases of the digestive system. Every 6 years on average expected 10 to 11 deaths per 10,000 people per site. Mortality rates from this cause are intermediate although variations between zones and / or periods are not significant.

12. Chapter XII Diseases of the skin and subcutaneous tissue. Every 6 years on average expected 2 to 3 deaths per 10,000 people per site. No significant differences between areas for the same period were observed. But this cause mortality was lower in the period 2007-2012 compared to 2000-2006 in the degraded area (OR: 0.40 IC (95\%) 0.208-0.780).

13. Chapter III Diseases of the musculoskeletal system and connective tissue. Every six years an average of 4 to 5 deaths expected by 10,000 people per site. Increase deaths from this cause in the area degraded in relation to the area with ecosystem integrity over the period 2007-2012 (OR: 1.72 IC (95\%) 1.021 to $2.898)$. That is, there is a $63.2 \%$ probability that death from this cause is associated with the degraded area. This area constitutes a risk factor. In turn, increased deaths degraded area during the period 2007-2012 compared to 2000-2006 (OR: 1.38 IC (95\%) 1.126-1.701).

14. Chapter XIV Diseases of the genitourinary system. Every 6 years on average expected 5 to 6 deaths per 10,000 people per site. Their variations between zones and / or periods are not significant. 
15. Chapter XV Pregnancy, childbirth and postpartum. Every six years an average of 1 to 2 is expected deaths per 10,000 people per site. No significant differences between areas for the same period were observed. However, mortality from this cause increased in the period 2007-2012 compared to 2000-2006 in the area of degraded sites (OR: 2.63 IC (95\%) 1.122-6.150).

16. Chapter XVI Certain conditions originating in the perinatal period. Every 6 years on average expected 5 to 6 deaths per 10,000 people per site. The changes were not significant.

17. Chapter VII congenital malformations, deformations and chromosomal abnormalities. Every 6 years on average expected 4 deaths per 10,000 people per site. No significant differences between areas for the same period were observed. However, mortality from this cause increased in the period 2007-2012 compared to 2000-2006 in the area of degraded sites (OR: 1.35 IC (95\%) 1.056-1.731).

18. Chapter VIII Symptoms, signs and abnormal clinical and laboratory findings, not elsewhere classified. Every six years an average of 4 deaths per 10,000 inhabitants is expected by site. Mortality from this cause is less degraded area in relation to the area with ecosystem integrity in the period 2000-2006 (OR: 0.63 IC (95\%) 0.430- 0.929) but not in the period 2007-2012 (OR: 1.69 CI (95\%) 1.003-2.850). The probability that deaths from this category are associated with degraded area ranges from 38.7 to 62.8. This variable performance is linked to the data set (the mode of classification) rather than the possible association event and being factor.

20. Chapter XX External causes of mortality. Every 6 years on average expected 14 to 15 deaths per 10,000 people per site. No significant differences were observed between zones. However, mortality increased in the period 2007-2012 compared to 20002006 (OR: 5.24 IC (95\%) 4.536-6.063) at the sites of the area degraded.

In short, the area categorized by the spatial model as degraded area is a risk factor given the increased mortality observed: neoplasms (2), diseases of the circulatory system (9), endocrine, nutritional and metabolic diseases (4); infectious or parasitic diseases (1) and musculoskeletal disorders or connective tissue (13). The causes with increased mortality in degraded areas correspond to endocrine, nutritional and metabolic diseases (4), musculoskeletal disorders or connective tissue (13), congenital malformations, deformations and chromosomal abnormalities (17) and pregnancy, childbirth or postpartum (15). Also it was observed that the nervous system diseases (6) increased mortality regardless of the area. Mortality from mental or behavioral disorders (5) turned out to be higher in areas with ecosystem integrity.

\section{Discussion}

The field of health and environment hazard identification and risk characterization seeks to control the occurrence of adverse effects. The risk is often expressed in quantitative terms of probability and there is, implicitly or explicitly, an acceptable risk is rarely zero. For example, in the study of the occurrence of a specific cancer is usually established as an acceptable risk, an increased incidence of 1 case in 10,000, 100,000 or 1 if a case per 1,000,000 exposed to pollutant over a lifetime (Garcia, 2015).
In this context, the fundamental element of environmental epidemiology studies is assessing human exposure. This examines the association between risk factors and adverse health effects. These assessments made by different modeling approaches have been strengthened by the use of GIS and geostatistical techniques (Nuckols et al, 2004).

Beyer \& Hatch, 1999 reported among the purposes of geographical models used in risk assessment, the use of available data to estimate exposure through the environment in specific geographic locations. Examples: 1. away with models assuming that exposure decreases with distance from the source; 2. through Monte Carlo simulations to characterize the level of uncertainty in the estimate; 3. applying Bayesian statistical probabilities integrating observational data with expert judgment to generate a probability of occurrence of an event (Aylin et al 1999, Elliott et al 2004).

A geographic model can contribute to the monitoring of a region to estimate pollutant concentrations in all times and places of the study area and whose precision depends on the quality of information available. Although environmental laboratory data contribute to a diagnosis of a site, this diagnosis is dependent on the applied sampling design (sample number, location, time of sampling, depth, medium analyzed substances / components considered, technical, instrumental, among others). In general, most environmental measures are revealed fixed stations and their number is usually limited. In that case the geographical patterns of exposure could reflect differences in the data record (Jarup, 2004).

Some authors claim that the direct methods of measuring exposure are considered better than indirect to evaluate the effect of pollutants on a population. Indirect methods are used to monitor and evaluate emission sources. Assume a link between the health of the population and a source-specific emission (Cordioli et al, 2013). While there is agreement in the scientific community on the need to have methods to detect possible ecological crises caused by human activities, there is no agreement on the concepts and methodology used in the development of an environmental alarm (Berry 1993; Shrader- Frechette, 1994).

It should be considered in the baseline of a study that ecosystems are not static in their composition and structure (Velez, 2004). The concept of ecological integrity is associated with the ability to maintain a balanced and integrated biophysical system, with a species composition and functional organization comparable to natural ecological systems of a particular region (Karr, 2000). Clearly it is not possible to measure or monitor the integrity of ecosystems directly, so the developed methodologies focus on the search for quantitative indices based on different aspects of the structural components and functional processes of ecological systems (Cairns et al, 2000). The use of the concept of ecological integrity derives from the scientific need to determine the minimum thresholds to support applications. This is to determine the level of human influence starts irreversible destruction of the ecosystem.

There are numerous indicators -to make diagnosis of individuals, populations, communities-which generate heated debate about the usefulness and scope of the proposed methodologies and indices (Reynoldson \& Metcalfe-Smith, 1992).

When there are many productive activities in a territory, and these are recognized in the literature by changes in the environment and whose impacts affect the health of the popula- 
tion, the question arises: how to establish a rapid and economical diagnosis? And it is possible to settle liabilities when multiple sources?

Degradation processes in the ecosystem become evident when the impacts can be captured by studies qualitative. In this study, ecosystem degradation was evident in mortality data. The spatial model was developed in order to stratify the territory to maximize exposure contrast. And therefore, to permit the selection of population groups parallel to the geographic distribution of exposures.

The cumulative total number of deaths in relation to the average reference population did not change between the periods analyzed for the study area. Neither he changed the dominant cause of death nor trends between the number of sites and number of specific deaths. However variability of mortality is observed when the space dimension is incorporated. An increase in mortality rates in areas of exposure with respect to non-exposure was observed.

In relation to the sensitivity of the exposure metric, the different dimensions of exposure contributed to the description of scenarios. According to:

1) The classification of land use in terms of environmental impact and health risks of the population, according to existing records in the literature (intensity or degree of adversity of the environment);

2) Living in the affected zone. The interaction between residential and productive use was measured by the distance. This informs about the degree of possibility or certainty of exposure (spatial dimension);

3) The classification of the population exposed to incorporate as historical production activity (according to land use that are in the vicinity of the houses) reduces the universe of exposure to a plausible range for a specific population group (temporal dimension). Stratification obtained by the spatial model was confronted with the deaths over 12 years. In this case mortality in relation to morbidity minimizes inaccuracies of latency of some diseases.

It is obvious that the processes of cause / effect cannot be focused individually, multiple farms scenarios require more integrated scales and here the spatial aspects play a key role perception.

In this context, the International Agency for Research on Cancer (IARC) made a classification of risks of pollution in general rather than individual substances. Of research, said: "Although the composition of pollution and exposure levels vary dramatically from one area to another, the conclusions are valid for all regions of the world," "Studies show that the greater the exposure, the risk cancer is increasing" (IARC 2013).

This causes the integrated information becomes a critical input to improve the formulation and implementation of public policies and decision processes.

WHO points out, "a healthier environment could significantly reduce the incidence of cancer, cardiovascular disease, asthma, infections of the lower respiratory tract, musculoskeletal diseases, road traffic injuries, poisonings, and drowning". Also among the environmental illnesses are diarrhea, poisoning, infections in general, malnutrition; and perinatal conditions (Prüss-üstün A \& C. Corvalán, 2006).

This study showed higher mortality in the area degrad- ed by those causes classified in the literature as environmental origin (neoplasms, diseases of the circulatory system, endocrine, nutritional or metabolic, infectious or parasitic diseases and diseases of the musculoskeletal system and connective tissue) and increased mortality for the second period (endocrine, nutritional and metabolic diseases, musculoskeletal disorders or connective tissue, for congenital malformations, deformations and chromosomal abnormalities and pregnancy, childbirth and postpartum).

The constructed model has a high degree of certainty (high probability of being correct) based on the knowledge available at the time of this work. A utility of modeling is predicting spatial changes that affect more than one generation (Navoni, 2014), it is a tool for analyzing possible scenarios affecting sustainability.

\section{Conclusion}

The space model developed proved to be a good study design since the purpose of stratifying the territory was to maximize exposure contrast. The reference area corresponds to an environmental unit, and thus inferences obtained from analysis of mortality, indicating a differential behavior according to variations in environmental conditions. The value of ecosystem integrity of the site is a measure of exposure.

If the design of the space model is based on a simple and logical reasoning, based on readily available data and if both data and the model is made explicit, then it is possible to implement a model of qualitative exposure. The implementation of this type of instrument can prove highly appropriate in organizations that support the risk management strategies of the population. These organizations require tools, agile for displaying risk scenarios, that can be shared with the same population and that can be implemented in areas with little infrastructure and technical support.

\section{Reference}

1. Petras, J., Veltmeyer, H. Juicio a las multinacionales. (2007) Inversión extranjera e imperialism, Editorial Popular 228.

2. Uharte, Luis Miguel. "Política social y democracia: un "nuevo" paradigma". (2005) EnRevista Venezolana de Economía y Ciencias Sociales 11(3): 93- 114.

3. Corvalán, C.F.,Kjellström, T.,Kirk R.S. Health, Environment and Sustainable Development. (1999) Identifying links and Indicators to Promote Action by Epidemiology Resources Inc 10(5): 650-660

4. Prüss-Üstün, A., Corvalán, C. Ambientes saludables y prevención de enfermedades. Hacia una estimación de la carga de morbilidad atribuible al medio ambiente. (2006) Organización Mundial de la Salud 19.

5. Junta de, A. Consejería de medio ambiente y ordenación del territorio. Naturaleza de la aproximación ecosistémica. (2015) Documento técnico 3: 49-96.

6. Vélez Restrepo, L.A., Gómez Sal, A.. Un marco conceptual y analítico para estimar la integridad ecológica a escala de paisaje. (2008) Arbor 184(729).

7. Eastman, R.J., Kyem, P.A.K., Toledano, J., et al. GIS and Decision Making. USA. (1993) Clark Universty, UNITAR IV.

8. Barredo Cano, J I. Sistemas de información geográfica y evaluación multicriterio en la ordenación del territorio. (1996) RA-MA Editorial.

9. Santos Preciado J.M. El planteamiento teórico multiobjetivo multicriterio y su aplicación a la resolución de problemas medioambientales y territoriales, mediante los S.I.G. (1997) Raster Espacio, Tiempo y 
Forma 10:129-151.

10. Florent, J.,Theriault, M.,Musy, A. Using GIS and outranking multicriteria analysis for land-use suitability assessment. (2001) International Journal of Geographical Information Science. 15(2):153-174.

11. Pietri, D.D., Patricia, D., Patricia, M. Evaluación multicriterio de la exposición al riesgo ambiental mediante un sistema de información geográfica en Argentina. (2011) Rev Panam Salud Pública 30(4): 377 387.

12. COPADE. Programa De Desarrollo De Información Territorial (Diter): Unidad de Sistemas de Información Territorial. (2014) Ministerio de Desarrollo Territorial.

13. Instituto Nacional de Estadística y Censos (INDEC). Censo Nacional de Población, Hogares y Viviendas (2010) Series 2, Argentina.

14. Naciones Unidas. Manual de sistemas de información geográfica y cartografía digital. (2000) ST/ESA/STAT/SER.F/79 228.

15. Comisión Económica Para América Latina y el Caribe (CEPAL). Población, territorio y desarrollo sostenible. (2012) Naciones Unidas 243.

16. Driven, M., Candia, D.B., Pena, C., et al. Hacia una nueva definición de "rural" con fines estadísticos en América Latina. (2011) Documentos de proyectos, $\mathrm{N}^{\circ} 397$ (LC/W.397).

17. Arcgis10.2 ESRI, USA ESRI. Gis software. ArcGIS 9.31. USA 22.

18. Clasificación Estadística Internacional de Enfermedades y Problemas relacionados con la Salud - Décima Revisión (CIE-10). (1992) Organización Panamericana De La Salud 2: 173.

19. EPIDAT Programa para análisis epidemiológico de datos tabulado. Versión 3.0. (2003) Organización Panamericana de la Salud.

20. Garcia, S. I. La necesaria evaluación de impacto en salud de la explotación de gas de esquisto. (2015) Acta bioquím clín latinoam 49(1). 21. Nuckols, J.R.,Ward, M.H., Jarup, Y.L. El uso desistemas de información geográfica para la evaluación de la exposición en Estudios de epidemiología ambiental. (2004) Envir Health Perspect 112 (9): $1007-$ 1015.

22. Beyea, J. Geographic exposure modeling: a valuable extension of geographic information systems for use in environmental epidemiology. (1999) Environ Health Perspect 107(1): 181-190.
24. Aylin, P., Maheswaran, R., Wakefield, J., et al. A national facility for small area disease mapping and rapid initial assessment of apparent disease clusters around a point source: the UK Small Area Health Statistics Unit. (1999) J Public Health Med 21(3): 289-298.

25. Elliott, P., Wartenberg, D. Spatial epidemiology: current approaches and future challenges. (2004) Environ Health Perspect 112(9): 9981006.

26. Jarup L. Health and environment information systems for exposure and disease mapping, and risk assessment. (2004) Environ Health Perspect 112(9): 995-997.

27. Cordioli, M., Ranzi, A., De Leo., et al. A Review of Exposure Assessment Methods in Epidemiological Studies on Incinerators. (2013) Journal of Environmental and Public Health 12.

28. Berry, R.J. Ethics and decisions. (1993) Environmental dilemmas.

29. Shrader Frechette, K. Risk and ethics. In Radiation and society: Comprehending radiation risk. V. 1. A report to the IAEA with collected papers. (1994) Proceedings of an international conference 26(13): 167-182.

30. Vélez, L.A. Aportaciones de la ecología del paisaje a la ordenación territorial. Integridad ecológica en áreas de influencia de Medellín, Colombia. 2004 Univ de Alcalá. 320.

31. Karr, J.R. Health, integrity, and biological assessment: The importance of measuring whole things, en: Pimentel, D.; Westra, L. and Noss, R. F. (Eds.) (2000) Ecological Integrity: Integrating environment, conservation, and health, Island Press 209-226.

32. Cairns, M.A., Patricia K.H., Roman, A., et al. Tropical Mexico's recent land-use change: a region's contribution to the global carbon cycle. (2000) Ecological Applications 10(5): 1426-1441.

33. Reynoldson, T.B., Metcalfe-Smith, J.L. An overview of the assessment of aquatic ecosystem health using benthic invertebrates. (1992) J Aquatic Ecosystem Health 1: 295-308.

34. IARC. Outdoor air pollution a leading environmental cause of cancer deaths. (2013) WHO 17.

35. Navoni, J.A., D. De Pietri., Olmos, V., et al. Human health risk assessment with spatial analysis: Study of a population chronically exposed to arsenic through drinking water from Argentina. (2014) Sci Total Environ 499: 166-174.
Ommega Online Publishers

Journal Title: Journal of Environment and Health Science (JEHS)

Journal Short Name: J Environ Health Sci
Journal ISSN: 2378-6841

E-mail: environmentalscience@ommegaonline.org Website: www.ommegaonline.org 